\title{
3D Printing and Prototyping Manifolds for Microtubular Solid Oxide Fuel Cells (mSOFCs)
}

\author{
A. D. Meadowcroft ${ }^{1}$, K. Gulia ${ }^{2}$, K. Kendall ${ }^{3}$ \\ ${ }^{1}$ Chemical Engineering, University of Birmingham, Edgbaston, B15 2TT, UK \\ ${ }^{2}$ Metallurgy \& Materials, University of Birmingham, Edgbaston, B15 2TT, UK
}

\begin{abstract}
A significant issue for the microtubular Solid Oxide Fuel Cell (mSOFC) is the complex inlet manifold for the fuel entry. Hundreds or even thousands of gas connections must be made to the tubes, with equal fuel flow required in each tubular anode compartment. This paper shows how rapid prototyping of fuel inlet manifolds may be used to create test manifolds and to optimise the fuel pathways economically. As tube diameter is reduced in future, it is expected that this $3 D$ printing process will become even more relevant to $\mathrm{mSOFC}$ development.
\end{abstract}

Keywords: Fuel Cells, 3D Printing, Prototyping, Manifolds, ABS.

\section{Introduction}

The first microtubular SOFCs (mSOFCs) appeared in the early 1990s (1-5). The two main benefits were rapid start-up and high power density compared to the larger diameter tubular designs in vogue at that time (6-8). The downside of introducing larger numbers of small diameter tubes was the problem of connecting hundreds or even thousands of tubes to the inlet fuel supply. For example, the 1000 tube demonstration produced in 1997 used metal manifolds which required complex, expensive machining and assembly operations to build the stack shown in Fig 1. Forty manifolds were machined with 25 injection tubes on each to provide the gas connection to the ceramic microtubes.

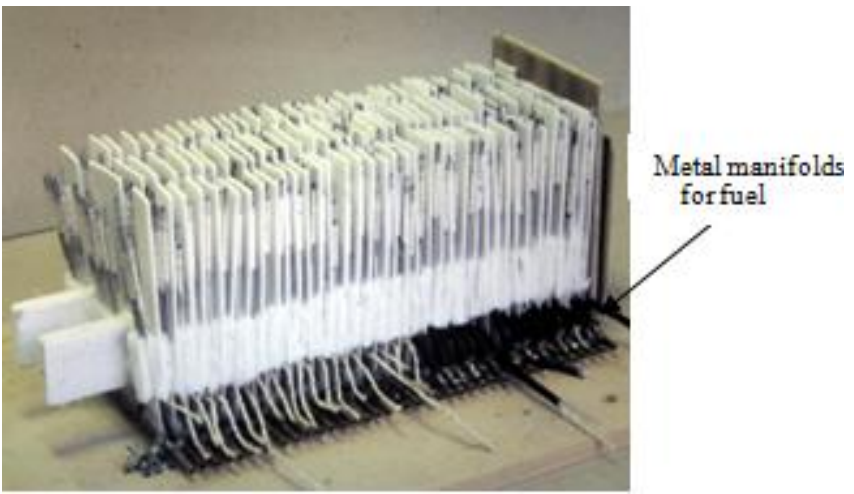

Figure 1: One thousand tube mSOFC stack showing metal manifolds for fuel inlet

Additive manufacturing for rapid prototyping is a possible solution to this problem (9). Additive Manufacturing or 3D printing, as it is known commonly, is suggested to be the next industrial revolution. The major advantage of the technique is the ease of prototyping, ease in printing complicated designs and visualisation of the concepts. In this paper, a design for mSOFC manifolds has been evolved, fabricated by $3 \mathrm{D}$ printing and tested in a 64 tube $\mathrm{mSOFC}$ stack. The results show that there are benefits of low mass, ease of assembly and improved economics.

\section{Design Manifold}

The initial design of the 4 tube sub-stack fuel inlet manifold is shown in Fig 2. The concept is based on the original mSOFC patent (10) which describes a cold inlet seal to the ceramic fuel cell tube with a warm-up zone as the tube goes into the hot-box at $700^{\circ} \mathrm{C}$ with an internal Partial Oxidation (POX) Catalyst at the hot entry to process hydrocarbon fuel with a premixed air formulation (11).

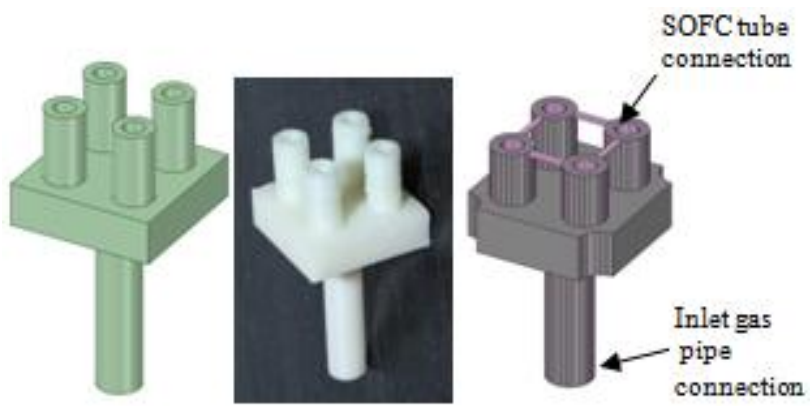

Figure 2 left; original CAD design for fuel feed to four fuel cell tubes in sub-stack; middle; photo of 3D printed part; right; final version designed with support structure and location cut-outs at corners

This part was evaluated in a substack test furnace as shown in Fig 3. Hydrogen was used as the fuel at $0.61 / \mathrm{min}$ and air was flowed over the cathode outer tube surfaces at $61 / \mathrm{min}$. The power output at $700^{\circ} \mathrm{C}$ mean temperature and $2.8 \mathrm{~V}$ for 4 tubes in series was more than $20 \mathrm{~W}$. 


\section{International Journal of Science and Research (IJSR) \\ ISSN (Online): 2319-7064}

Index Copernicus Value (2013): 6.14 | Impact Factor (2014): 5.611

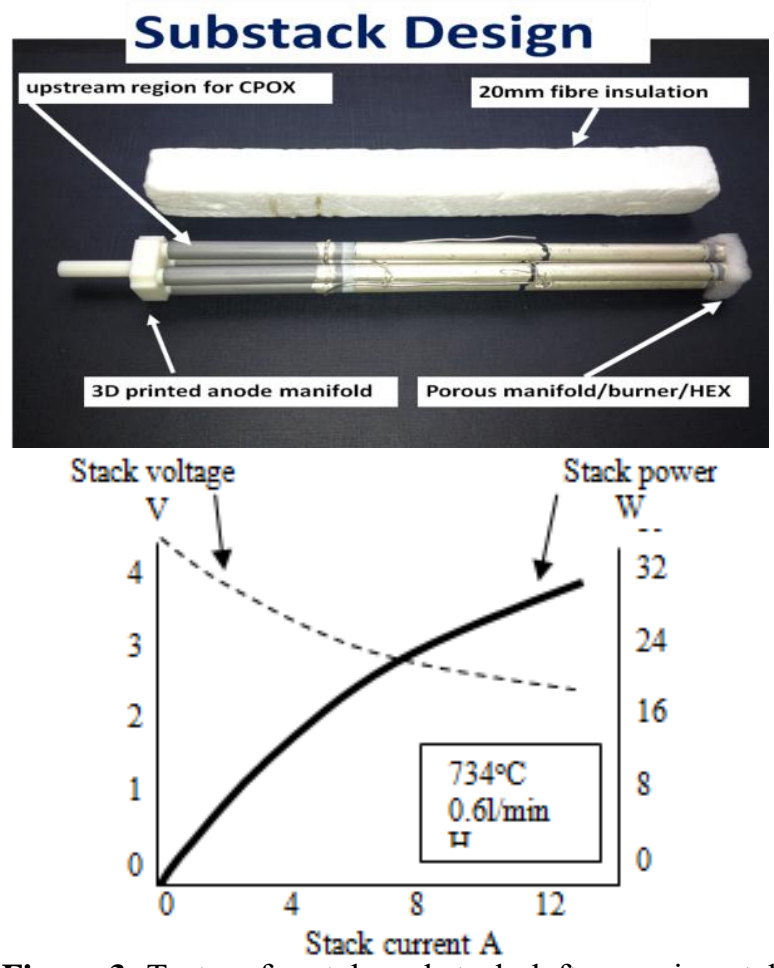

Figure 3: Test on four tube substack; left; experimental arrangement; right; result on four-tube substack

In order to apply this to a 64 tube mSOFC stack, another 3D printed part was designed to give equal tube flows from the fuel inlet pipe, via 16 substack manifolds, to the 64 tubes in the hot SOFC stack as shown in Fig 4. This was optimized over several experimental iterations by adjusting the internal geometry to obtain measured flows which were similar for all 64 tubes.

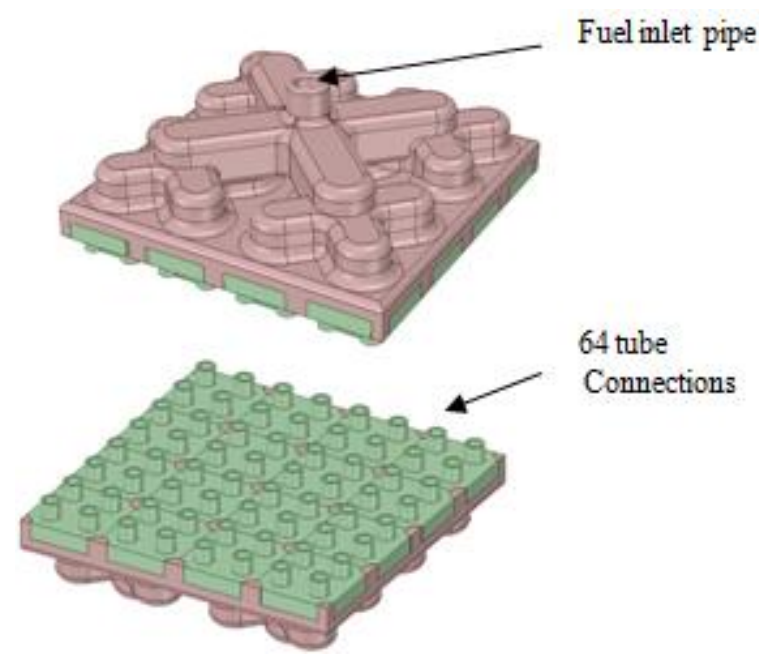

Figure 4: Top; top view of manifold showing fuel inlet; Bottom; bottom view showing 64 tube connections

\section{3D Printing of the Manifolds and the Fuel Cell Tubes Experimental Demonstration}

HP 3D printer was used to prototype the manifolds and the fuel cell tubes. ABS (Acrylonitrile Butadiene Styrene) is the material used for building the component. The CAD design is sketched in the Solidworks of the manifolds and fuel cell tubes, converted in the STL (Stereolithography file format) and fed to the printer for building. Following figure 5 shows the STL file of the Fuel cell tubes and the manifold.

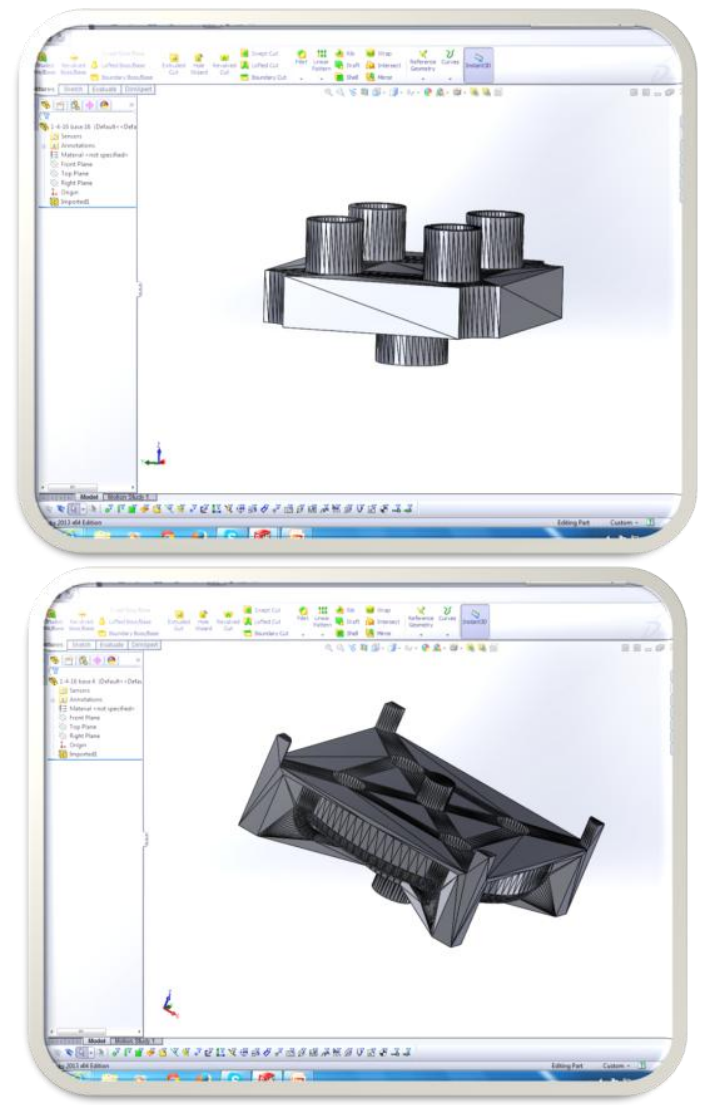

Figure 5: STL view of the Fuel tubes cell (LHS) and the Manifold (RHS) in Solidworks

The 3D printer mathematically slices the files and begins building the toolpath. The toolpath is defined by the shape of the component. The support structures are generated to help the component orientation attach to the build plate. This support structure is soluble and provides the actual model. The deposition of the ABS material begins with a process called FDM (Fused deposition Method) where small strings of molten ABS layers to add on the material. The material hardens soon after the extrusion from the heated nozzle. ABS is heated past its transition temperature of $105^{\circ} \mathrm{C}$ or $221^{\circ} \mathrm{F}$ (12).

The nozzle head moves in $\mathrm{X}, \mathrm{Y}$ and $\mathrm{Z}$ directions, hence building the component from bottom up. The CAD slices define the toolpath which is followed by the nozzle for the deposition of the material. The toolpath is controlled by the CAM (Computer Aided Manufacturing) Software. The stage is moved lower to accommodate the build.

With the progression in the use of $3 \mathrm{D}$ printers, lot many materials are included in the array that can be easily printed. ABS, PEEK, PLA, Rubber, Nylon, Biomaterials, and even chocolates are printed using various printing techniques (13).

$3 \mathrm{D}$ printing of the prototypes is especially advantageous in the concept visualisation. In this study, the design of the fuel cells was rapidly changed and evaluated by fitting it in the experiment. Cell performance equalled state of the art at the time. However deformation of the plastic as is shown in Figure 6 in the picture below.

\section{Volume 4 Issue 11, November 2015}




\section{International Journal of Science and Research (IJSR) \\ ISSN (Online): 2319-7064}

Index Copernicus Value (2013): 6.14 | Impact Factor (2014): 5.611

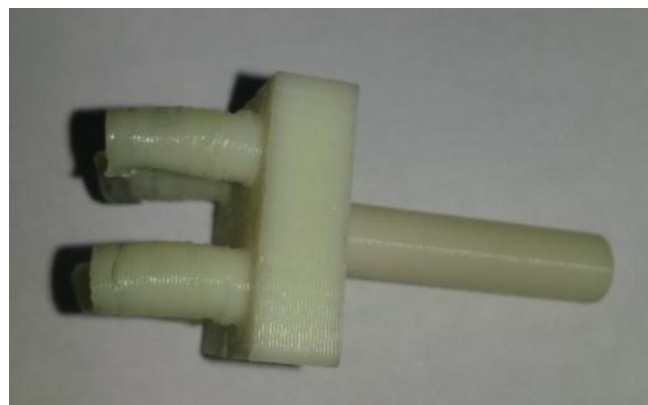

Figure 6: Deformed ends of the tubes

Smaller Manifolds were designed and 3D printed as is shown in Figure 7 below. These smaller manifolds were connected to the cells using silicone rubber tubing. The following picture shows the assembled sub-stacks using the smaller manifolds.

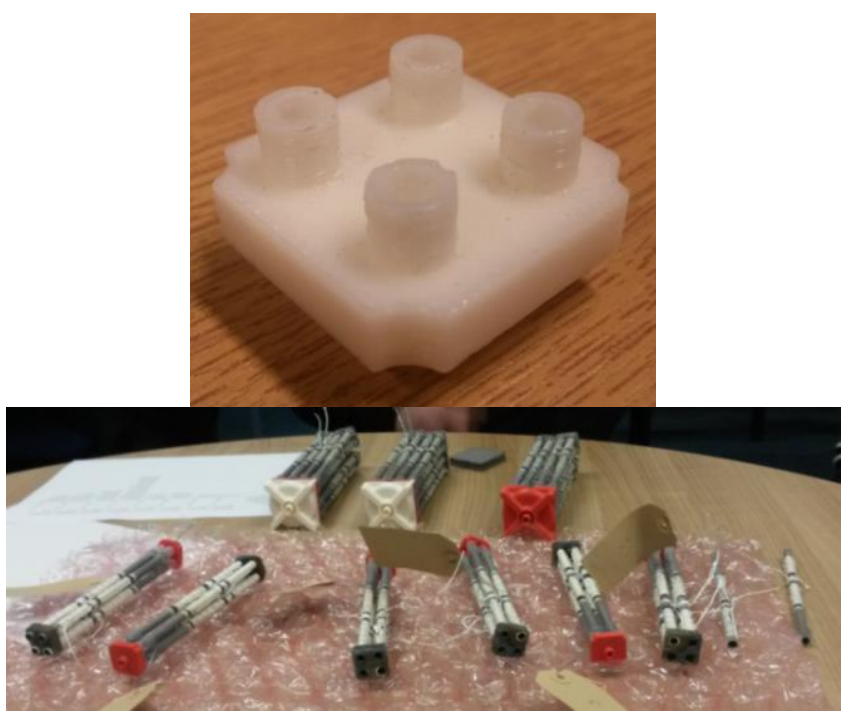

Figure 7: Smaller Manifolds (LHS) and Assembled substacks with the smaller Manifolds (RHS)

\section{Experimental Demonstration Conclusions}

The experimental demonstration was carried out on a 64 tube stack assembled as in the diagram of Fig 5. Sixteen substacks were first built and tested to ensure satisfactory power output in hydrogen at $700^{\circ} \mathrm{C}$. Then these substacks were assembled into the full 64 tube stack which was then tested using hydrogen in the furnace illustrated in Fig 5.

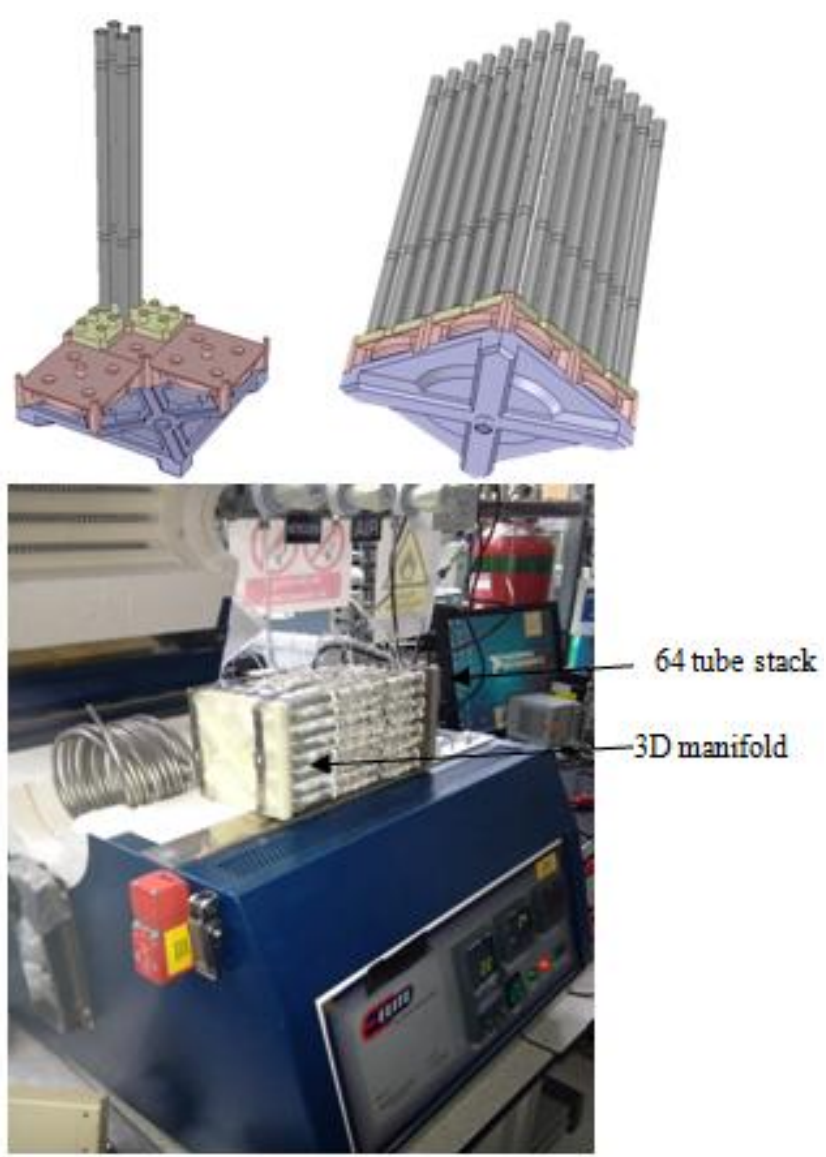

Figure 5: Top; diagram of stack assembly; middle; CAD of 64 tube stack built on 3D manifold; Bottom; photo of experimental version before inserting in furnace.

The test showed some gas leakage around the ABS manifolds. Silicone sealant was used to prevent gas leaks. Also there was some heat transfer from the hot fuel cell tubes out to the plastic manifolds, raising their temperature towards $100^{\circ} \mathrm{C}$ where softening and drooping was observed. This was prevented by inserting more Saffil wool insulation between the ceramic tubes at the inlet end, while also allowing cool air to circulate around the manifolds.

Further testing showed that the plastic manifold made by $3 \mathrm{D}$ printing could be successful in this fuel cell stack design. The advantages of rapid design evolution, low mass, and economic manufacture were clearly apparent when compared with the previous steel or ceramic manifolds. As the tubes are made in smaller diameters, with larger numbers of cells, it is expected that additive manufacture will become even more advantageous.

\section{Conclusions}

Microtubular solid oxide fuel cells have had a significant difficulty of feeding inlet fuel gas to hundreds or even thousands of fuel cell tubes in hot stacks for portable applications (14). Previously metal or ceramic manifolds were used with penalties of excessive weight, assembly problems and high costs. We have shown that additive processing of such complex fuel inlet manifolds has advantages in

- Rapid prototyping

- Evolution of optimized flow designs 


\section{International Journal of Science and Research (IJSR) \\ ISSN (Online): 2319-7064}

Index Copernicus Value (2013): 6.14 | Impact Factor (2014): 5.611

- Low mass manifolds

- Economic initial production

- Future: Even though the fuel tubes cell were printed with the ABS, which occasionally failed to withstand the temperature, therefore, this led to the thinking of printing these with Ceramics (15).

\section{Acknowledgment}

The authors gratefully acknowledge the support of FCH JU for Project SAPIENS which is funded under Europe's Fuel Cell and Hydrogen Joint Undertaking (FCH JU) for 36 months, from November 1, 2012 (Contract Number 303415).

\section{References}

[1] K. Kendall, in Proceedings of the International Forum on Fine Ceramics, 1992. Japan Fine Ceramics Center, Nagoya.

[2] M. Kendall, Tubular cells: a novel SOFC design, Final Year Thesis. 1993, Middlesex University

[3] K. Kendall and G. Sales, A rapid heating ceramic fuel cell, in Ceramics in Energy Applications, Institute of Energy, London pp.55-63 (1994).

[4] M. Prica, T. Alston, and K. Kendall, Mechanical and thermal properties of a 200 tube SOFC reactor, in Proceedings of the Fifth International Symposium on Solid Oxide Fuel Cells, U. Stimming, et al., Editors. 1997, Electrochemical Society Inc: Pennington. p. 619625.

[5] K. S. Howe, G. J. Thompson and K. Kendall, Microtubular solid oxide fuel cells and stacks, J Power Sources 196, 1677-86 (2011).

[6] A.O. Isenberg, Energy-conversion via Solid Oxide Electrolyte Electrochemical-Cells At HighTemperatures, Solid State Ionics, 3-4, 431-437 (1981).

[7] U. B. Pal and S.C. Singhal, Electrochemical VaporDeposition Of Yttria-Stabilized Zirconia Films. Journal of the Electrochemical Society, 137(9) 29372941(1990).

[8] S.C. Singhal and K. Kendall, in High Temperature Solid Oxide Fuel Cells, ch.8 Cell and Stack Designs, Elsevier, Oxford 2003.

[9] Patent Publication No. WO 94/22178 Solid Oxide Fuel Cell Structures, by K Kendall to Keele University (1994).

[10] T. Alston, T., et al., A 1000-cell SOFC reactor for domestic cogeneration. Journal of Power Sources, 71, 271-274(1998).

[11] FDM 3D Printing Technology in Manufacturing Composite Elements Dudek P, Archives of Metallurgy and Materials, Dec 2013, Vol.58 (4), pp.1415-1418

[12] Stratasys Expands FDM and PolyJet 3D Printing Material Options Business Wire, Jan 29, 2015

[13] US Patent Appl number 11/598593 'Portable fuel cell' by K and M Kendall to Adelan Ltd, 2004.

[14] A D Meadowcroft, S Howroyd, K Kendall, M Kendall, Testing mSOFCs in Unmanned Air Vehicles, SOFC xiii Okinawa, Oct 2013, The Electrochemical Society, Pennington NJ.

[15] Stereolithographic 3D Printing by Using Functional Ceramics Particles Kirihara, Soshu Journal of the
Society of Powder Technology, Japan, 2014, Vol.51(7), pp.519-526 2014 